\title{
A Pós-Graduação stricto sensu em Biodiversidade Tropical no Amapá: uma experiência em construção
}

\section{Graduate Study in Tropical Biodiversity in Amapá: an experience in construction}

\section{El Postgrado stricto sensu en Biodiversidad Tropical en Amapá: una experiencia en construcción}

Helenilza Ferreira Albuquerque Cunha, doutora em Ciências da Engenharia Ambiental pela Universidade de São Paulo.Endereço: Rodovia JK, km 2 - Marco Zero - Macapá, AP. Telefone: (96) 3312-1757. E-mail: helenilzacunha@unifap.br.

Alan Cavalcanti da Cunha, doutor em Hidráulica e Saneamento pela Universidade de São Paulo. Endereço: Rodovia JK, km 2 - Marco Zero - Macapá, AP. Telefone: (96) 3312-1757. E-mail: alancunha@unifap.br.

José Maria Cardoso da Silva, doutor em Zoologia pela University of Copenhagen (Dinamarca) e vice-presidente executivo dos Programas de Campo da Conservação Internacional. Endereço: Rua Antonio Barreto, 130, $4^{\circ}$ andar, sala 406, Ed. Village Office - Umarizal - Belém, PA. Telefone: (91) 3225-3848. E-mail: j.silva@conservacao.org.

\section{Resumo}

A criação do Programa de Pós-Graduação em Biodiversidade Tropical (PPGBIO) foi um marco histórico que uniu o esforço de quatro instituições distintas com os mesmos objetivos (Universidade Federal do Amapá, Instituto de Pesquisas Científicas e Tecnológicas do Estado do Amapá, Empresa Brasileira de Pesquisa Agropecuária e Conservação Internacional). Este estudo descreve o perfil dos candidatos junto ao programa e seus resultados mais expressivos nesta modalidade de parceria institucional da pós-graduação aprovada pela Capes. O êxito do programa imediatamente se refletiu principalmente na permanência de 
mais de $90 \%$ dos egressos do curso de mestrado no estado do Amapá, que atuam ou passaram a atuar em diversas instituições públicas e setores ambientais.

Palavras-chave: Pós-Graduação. Biodiversidade Tropical. Amapá. Experiência.

\section{Abstract}

The implementation of the Graduate Program in Tropical Biodiversity (PPGBIO) was a landmark that united four different institutions with the same goals (Universidade Federal do Amapá / UNIFAP, Instituto de Pesquisas Científicas e Tecnológicas do Estado do Amapá/IEPA,Empresa BrasileiradePesquisaAgropecuária/EMBRAPAAP and Conservation International/CI Brazil). This article describes the profile of the program's candidates and the most impressive results of this kind of institutional partnership of graduate study, approved by Capes. The program's immediate success is reflected in the fact that more than $90 \%$ of the graduating master's students have remained in the State of Amapá, working or becoming active in various areas of the environmental and biodiversity conservation sector.

Keywords: Graduate Study. Tropical Biodiversity. Amapá. Case Study.

\section{Resumen}

La creación del Programa de Posgrado en Biodiversidad Tropical (PPGBIO, sigla en portugués) fue un momento histórico que unió el esfuerzo de cuatro instituciones distintas con los mismos objetivos (Universidad Federal de Amapá, Instituto de Investigaciones Científicas y Tecnológicas del Estado de Amapá, Empresa Brasileña de Investigación Agropecuaria y Conservación Internacional). Este estudio describe el perfil de los candidatos al programa y sus resultados más expresivos en esta modalidad de colaboración institucional del posgrado aprobado por la CAPES. El éxito del programa inmediatamente se reflejó, 
principalmente, en la permanencia de más del 90\% de los egresados del curso de maestría en el estado de Amapá que actúan o pasaron a actuar en diversas instituciones públicas y sectores ambientales.

Palabras clave: Posgrado. Biodiversidad Tropical. Amapá. Experiencia.

\section{Introdução}

O avanço econômico na fronteira territorial da Amazônia', a partir do final da década de 1960, foi marcado pelo processo violento de ocupação e degradação ambiental característica das economias de fronteira, nas quais o progresso é entendido simplesmente como crescimento econômico infinito, baseado na exploração de recursos naturais percebidos como igualmente infinitos (BECKER, 2001). De fato, nesse modelo de ocupação, a economia segue o padrão boomcolapso. Ou seja, nos primeiros anos da atividade econômica, ocorre um rápido e efêmero crescimento na renda e no emprego (boom), seguido muitas vezes de um colapso social, econômico e ambiental (CELENTANO; VERISSIMO, 2007).

O grande desafio para os estados da Amazônia, que estão ainda distantes da zona de fronteira, é evitar que o modelo não sustentável que foi imposto a "ferro e fogo" no arco do desflorestamento seja repetido em outros setores da região (VIEIRA; SILVA; TOLEDO, 2005). A chave para frear o desmatamento na região e aumentar os indicadores de qualidade de vida da população regional é combinar a conservação e o uso sustentável de $83 \%$ da floresta amazônica com o uso intensivo, com amplo suporte tecnológico e infraestrutura adequada, para os 17\% de áreas já alteradas (Ibid.). Para atingir esses objetivos, entretanto, é necessária uma estrutura de inovação científica e tecnológica que agregue valor aos produtos da região. Essa estrutura, por sua vez, deve se organizar a partir de um sistema de formação de recursos humanos descentralizado, inovador e de alto grau de eficiência (DINIZ, 1996).

Nas últimas duas décadas, o Amapá tem se destacado pela implantação de políticas públicas direcionadas para a redução do
Padrão econômico voltado para a exportação, que, desde o início da colonização até hoje, é a motivação dominante na ocupação regional. A ocupação da Amazônia se fez em surtos devastadores ligados à valorização momentânea de produtos no mercado internacional, seguidos de longos períodos de estagnação. O fenômeno ocorreu a partir de iniciativas externas associadas a interesses econômicos, mas estes foram, via de regra, mal sucedidos na sua implementação, não conseguindo estabelecer uma base econômica e populacional estável, capaz de assegurar a soberania sobre a área (BECKER, 2001). 
desmatamento e pelo desenvolvimento de uma nova economia baseada no uso sustentável da floresta.

Um dos grandes avanços obtidos no Amapá foi a criação de um extenso corredor de biodiversidade que inclui unidades de conservação e cinco terras indígenas, totalizando cerca de 11 milhões de hectares ou 72\% da área territorial do Amapá (SILVA, 2007). O núcleo desse corredor é o Parque Nacional Montanhas do Tumucumaque (PNMT), que, com mais de 3,8 milhões de hectares, é uma das maiores unidades de conservação de uso restrito em florestas tropicais no planeta. O Corredor de Biodiversidade do Amapá inclui, além de grandes trechos de florestas tropicais de diversos tipos, savanas e trechos de manguezais, ecossistema considerado um dos mais complexos do ambiente marinho, não só pela diversidade biológica, mas pela diversidade funcional (SCHAEFFER-NOVELLI, 2001).

Os serviços ambientais derivados desse corredor não foram ainda estimados, mas, bem pesquisados e valorados, podem gerar empregos e renda muitas vezes superior ao atual estágio da economia estadual, que ainda é baseada fundamentalmente em atividades extrativistas e transferência de recursos da União (SILVA, 2007; SILVA, 2011).

Com a criação do Corredor de Biodiversidade para garantir a proteção do capital natural renovável do Amapá, a segunda fase necessária é criar as condições para que o desenvolvimento de uma economia inovadora possa ser de fato implementada. Isso deve ser feito com base no uso sustentável da floresta e dos demais recursos naturais disponíveis.

Uma primeira versão do Zoneamento Econômico Ecológico (ZEE) para o Amapá foi proposta. O ZEE foi detalhado para algumas áreas fora das unidades de conservação, visando prover as bases científicas e organizar a ocupação da terra nesses setores. Novas instituições de gerenciamento do território foram criadas, apesar de todas possuírem ainda estruturas defasadas e orçamentos limitados. Houve preocupação do governo estadual também com a formação 
de recursos humanos necessários para transformar a economia amapaense. A Universidade do Estado do Amapá (UEAP) foi criada com cursos complementares aos já existentes ou oferecidos pela Universidade Federal do Amapá (Unifap), dando ênfase a programas de graduação voltados à agregação de valor aos produtos da floresta e ecossistemas aquáticos.

Durante as consultas realizadas para o planejamento estratégico do Corredor de Biodiversidade do Amapá, vários setores da sociedade amapaense indicaram a necessidade de um programa de pós-graduação completo (mestrado e doutorado) com foco na formação de recursos humanos de alto nível para prover as instituições públicas e privadas que estavam surgindo ou que surgiriam com a consolidação do corredor e a criação de um novo modelo de desenvolvimento endógeno. Entretanto, o Amapá não tinha nenhuma instituição de ensino ou pesquisa com densidade suficiente de doutores para atender essa demanda.

A solução para dar uma resposta à sociedade amapaense foi estabelecer uma associação inédita entre quatro instituições para elaborar a proposta do PPGBIO à Capes. As quatro instituições parceiras foram: Universidade Federal do Amapá (Unifap), Instituto de Pesquisas Científicas e Tecnológicas do Estado do Amapá (lepa), Empresa Brasileira de Pesquisa Agropecuária (Embrapa Amapá) e Conservação Internacional (Cl-Brasil). A proposta do PPGBIO foi aprovada pela Capes em julho de 2006, com conceito quatro. O programa passou a oferecer cursos de mestrado e doutorado. As suas áreas de concentração são: a) caracterização da biodiversidade; b) gestão e conservação da biodiversidade; e c) uso sustentável da biodiversidade (UNIVERSIDADE FEDERAL DO AMAPÁ, 2005, 2008).

Este artigo descreve inicialmente a demanda e o perfil dos candidatos ao PPGBIO, com vistas às necessárias respostas institucionais de formação de recursos humanos. Posteriormente, é apresentado o perfil dos alunos selecionados pelo programa, considerando-se a origem, formação e as demandas locais. Essas informações foram obtidas a partir dos dados coletados das fichas 
de inscrição preenchidas pelos próprios candidatos, das informações obtidas nos relatórios e de publicações do programa (CUNHA, 2011). As variáveis consideradas de maior relevância foram: número de editais e candidatos inscritos e aprovados; formação profissional; vínculo empregatício; idade e sexo; instituição de ensino superior de origem e tempo de conclusão do curso de graduação; e, finalmente, a área de pesquisa de maior interesse. Algumas análises exigiram um breve suporte estatístico, para o qual se utilizou o software BioStat 5.0 (AYRES et al., 2007). Considerando a relevância do tema, o nosso objetivo é prover à sociedade e às instituições de ensino superior e de pesquisa uma referência para que a trajetória do PPGBIO possa ser estudada e mais bem compreendida, principalmente de forma quantitativa.

\section{Resultados}

Os resultados foram elencados na seguinte ordem: a) demanda e perfil dos candidatos do processo seletivo do mestrado; e b) perfil dos pós-graduandos do PPGBIO. Em seguida, esses resultados foram discutidos.

\subsection{Demanda e perfil dos candidatos do processo seletivo do mestrado}

a) Número de editais e candidatos inscritos e aprovados

O PPGBIO completou três anos em setembro de 2009 com quatro editais de seleção lançados. No processo seletivo, os candidatos são submetidos a uma fase eliminatória (prova de inglês e conhecimentos) e classificatória (análise de currículo e entrevista). O número de inscritos vem declinando ao longo do tempo, com o pico máximo no primeiro edital (Tabela 1). A porcentagem de aprovação variou de 4 a $17 \%$ do total de candidatos (Tabela 1). 
Tabela 1. Número total de inscritos e aprovados (2006-2009)

\begin{tabular}{|c|c|c|c|}
\hline Mestrado & Inscritos & Aprovados & Aprovação (\%) \\
\hline $1^{\circ}$ Edital 2006 & 127 & 22 & 17 \\
\hline $2^{\circ}$ Edital 2007 & 90 & 16 & 17 \\
\hline $3^{\circ}$ Edital 2008 & 121 & 5 & 4 \\
\hline $4^{\circ}$ Edital 2009 & 54 & 6 & 11 \\
\hline Total & $\mathbf{3 9 2}$ & $\mathbf{4 9}$ & $\mathbf{1 2 , 5}$ \\
\hline
\end{tabular}

b) Sexo e idade dos candidatos

Como pode ser observado na Tabela 2, não houve equilíbrio entre o número de candidatos de ambos os sexos (masculino - $\mathrm{M}$ e feminino - F). A média de idade foi de aproximadamente 30 anos, mas com uma perceptivel tendência de queda para ambos os sexos, com exceção do feminino em 2008, cujo aumento foi expressivo.

Tabela 2. Média de idade e sexo dos candidatos do PPGBIO (2006 a 2009)

\begin{tabular}{|c|c|c|c|}
\hline Mestrado & Masculino & Feminino & Média de Idade \\
\hline $1^{\circ}$ Edital 2006 & 68 & 59 & 32 \\
\hline $2^{\circ}$ Edital 2007 & 50 & 40 & 32 \\
\hline $3^{\circ}$ Edital 2008 & 49 & 72 & 33 \\
\hline $4^{\circ}$ Edital 2009 & 21 & 33 & 29 \\
\hline Total & $\mathbf{1 8 8}$ & $\mathbf{2 0 4}$ & $\mathbf{3 0 , 3}$ \\
\hline
\end{tabular}

Na Figura 1, estão indicados valores para $\chi 2$ (qui-quadrado) e $p_{1}$ os quais quantificam, respectivamente, o valor do teste de significância e a probabilidade das proporções dos candidatos por sexo. 


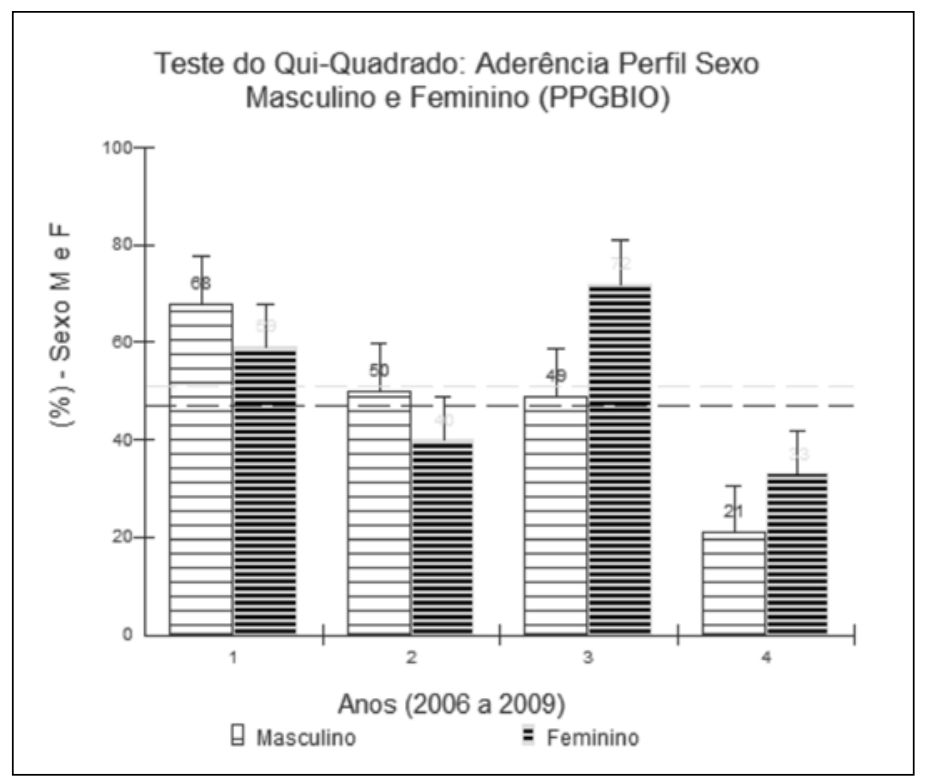

Figura 1. Teste $\chi 2(\alpha<0,05)$ comparativo entre as proporções médias dos sexos $\mathrm{M}$ e $\mathrm{F}$

Os valores de $\chi 2=15,584$ e $p=0,014$ são altamente significativos e indicam diferenças expressivas nas idades entre ambos os sexos, com inversão do perfil a partir de 2008.

c) Formação acadêmica

Quanto à formação acadêmica, predominaram, naturalmente, pela proposta do curso, candidatos com formação nas áreas de ciências biológicas, seguidas pelas áreas de humanas e exatas, nessa ordem (Tabela 3).

Tabela 3. Áreas de formação dos candidatos em números absolutos (2006 a 2009)

\begin{tabular}{|c|c|c|c|}
\hline Mestrado & Exatas & Humanas & Biológicas \\
\hline $1^{\circ}$ Edital 2006 & 34 & 41 & 52 \\
\hline $2^{\circ}$ Edital 2007 & 24 & 30 & 36 \\
\hline $3^{\circ}$ Edital 2008 & 24 & 41 & 56 \\
\hline $4^{\circ}$ Edital 2009 & 7 & 14 & 33 \\
\hline Total & $\mathbf{8 9}$ & $\mathbf{1 2 6}$ & $\mathbf{1 7 7}$ \\
\hline
\end{tabular}


De acordo com a Figura 2, as proporções entre as médias das áreas de formação são semelhantes, indicando a manutenção de um padrão de proporções no tempo.

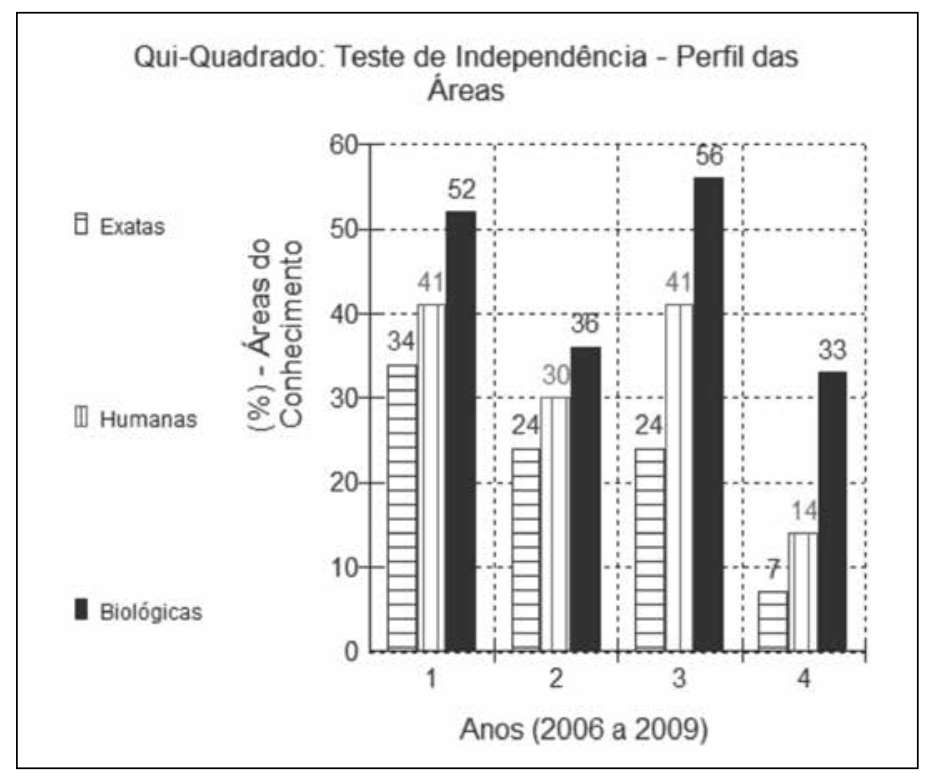

Figura 2. Teste $\chi 2(\alpha<0,05)$ comparativo das proporções médias entre as áreas dos candidatos

Os valores de $\chi 2=9,155$ e $p=0,1651$ não indicam diferenças significativas entre as proporções no período. Entretanto, no ano de 2009, esse padrão tendeu a se afastar da proporcionalidade em relação aos demais anos, mas ainda não foi suficiente para causar mudanças significativas (em que 1 = 2006, 2 = 2007, 3 = 2008 e 4 = 2009) .

d) Instituição de ensino superior de origem e tempo de conclusão do curso de graduação até o período de inscrição no processo seletivo.

Avaliando os anos de 2006 a 2009, em média, 51\% dos candidatos ao mestrado cursaram sua graduação no estado do Amapá, cuja distribuição foi a seguinte: em 2006, 40\% dos candidatos concluíram sua graduação no Amapá, 39\% na região amazônica e 19\% em outras regiões do País. Em 2007, 47\% dos candidatos concluíram sua graduação no Amapá, 32\% na região amazônica e 20\% em outras regiões do País. Em 2008, 59\% dos candidatos concluíram sua graduação no Amapá, 21\% 
na região amazônica e 19\% em outras regiões do País. Em 2009, 57\% dos candidatos concluíram sua graduação no Amapá, 11\% na região amazônica e 31\% em outras regiões do País.

Os dados concernentes ao tempo de formação dos candidatos, até o momento quando ocorreu o processo seletivo, foram obtidos a partir das médias anuais no período avaliado. Os candidatos inscritos em 2006 concluíram seus cursos de graduação em 5,9 anos. Os inscritos em 2007, em média, haviam concluído a graduação há 5,1 anos. Em 2008, os candidatos concluíram a graduação em 4,9 anos, enquanto que, em 2009, em média, concluíram seus cursos em 3,7 anos.

A Figura 3 mostra a tendência de diminuição do tempo médio de formação do candidato, calculada a partir do ato da inscrição e com início em 2006.

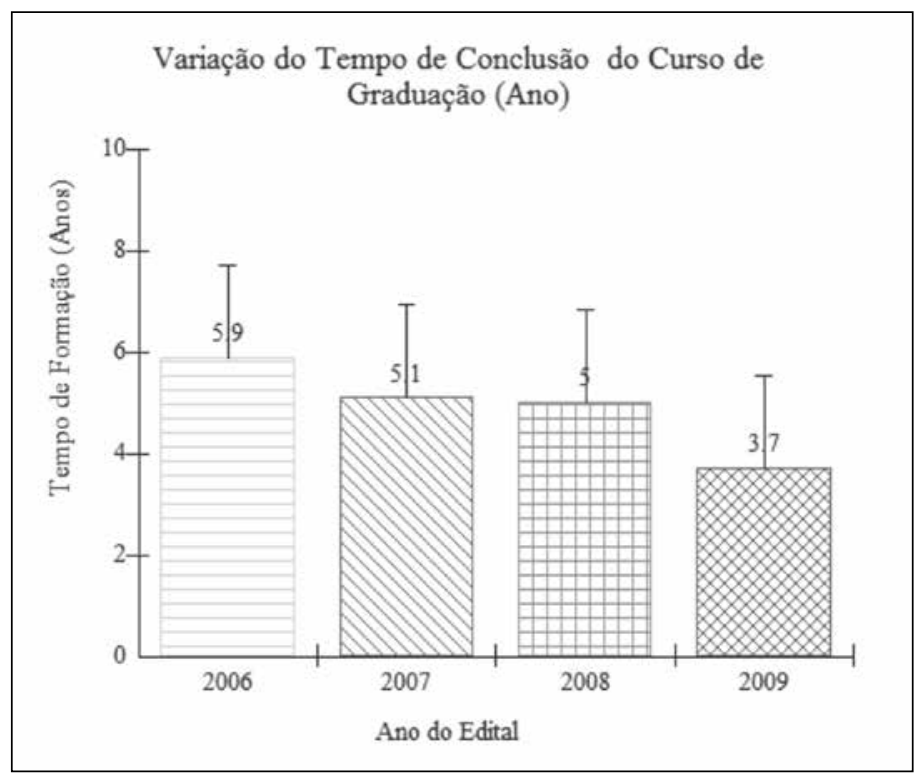

Figura 3. Variação do tempo médio de formação na graduação do candidato no ato da inscrição em função no período (erro com intervalo de dois desvios padrão)

e) Vínculo empregatício e profissão dos candidatos

Os candidatos ao mestrado possuem em sua maioria vínculo empregatício (66\% de um total de 392 inscritos) (Tabela 4). 
Tabela 4. Candidatos que possuem vínculo empregatício (2006 a 2009)

\begin{tabular}{|c|c|c|}
\hline Mestrado & Sim & Não \\
\hline $1^{\circ}$ Edital 2006 & 100 & 27 \\
\hline $2^{\circ}$ Edital 2007 & 60 & 30 \\
\hline $3^{\circ}$ Edital 2008 & 84 & 37 \\
\hline $4^{\circ}$ Edital 2009 & 27 & 27 \\
\hline Total & $\mathbf{2 7 1}$ & $\mathbf{1 2 1}$ \\
\hline
\end{tabular}

Em 2006, foi registrado que 20 candidatos trabalhavam na área ambiental. Em 2007, seis exerciam funções voltadas para a área ambiental. Em 2008, nove exerciam funções voltadas a essa área e, em 2009, apenas um, dos que trabalhavam, exercia atividades na área ambiental. As principais instituições registradas foram: Ibama, Secretaria de Meio Ambiente (Sema), Instituto de Pesquisa do Estado do Amapá (lepa), Embrapa Amapá, Eletronorte, Instituto de Floresta do Amapá (IEF) e Instituto de Meio Ambiente e Ordenamento Territorial (Imap).

A profissão de maior destaque foi na área da educação (60,75\%), na média dos anos de 2006 a 2009. Por exemplo, no período de 2006 a 2009 , respectivamente, $63,55,62$ e $63 \%$ dos candidatos que trabalhavam já atuavam como professores da rede pública estadual de ensino.

f) Área de pesquisa de maior interesse

Quanto à área de pesquisa de maior interesse para o ingresso no mestrado, a que mais se destacou foi a de gestão e conservação da biodiversidade. Na tabela a seguir, é possivel observar como esse perfil também está se modificando com o tempo, com uma significativa queda absoluta da primeira ao longo do triênio, mas mantendo-se a proporção relativa entre as três áreas. 
Tabela 5. Número de candidatos às áreas de pesquisa de maior interesse (2006-2009)

\begin{tabular}{|c|c|c|c|}
\hline Mestrado & $\begin{array}{c}\text { Gestão e conservação } \\
\text { da biodiversidade }\end{array}$ & $\begin{array}{c}\text { Caracterização da } \\
\text { biodiversidade }\end{array}$ & $\begin{array}{c}\text { Uso da } \\
\text { biodiversidade }\end{array}$ \\
\hline $1^{\circ}$ Edital 2006 & 88 & 24 & 15 \\
\hline $2^{\circ}$ Edital 2007 & 60 & 19 & 11 \\
\hline $3^{\circ}$ Edital 2008 & 66 & 31 & 24 \\
\hline $4^{\circ}$ Edital 2009 & 38 & 6 & 10 \\
\hline Total & $\mathbf{2 5 2}$ & $\mathbf{8 0}$ & $\mathbf{6 0}$ \\
\hline
\end{tabular}

Na análise da Figura 4, foi aplicada uma análise de variância (ANOVA) que indicou os seguintes resultados $(\alpha<0,05)$, com $\mathrm{H}$ acusando valor altamente significativo. Portanto, rejeitou-se a hipótese de nulidade (em que os escores entre as áreas independem do período nos quais estão inscritos) e aceitou-se a hipótese alternativa, isto é, a magnitude das médias de candidatos das áreas difere entre cada uma delas (1 = caracterização, 2 = gestão da conservação, 3 = uso da biodiversidade). Essa diferença ocorreu entre as áreas 1-3 (coluna central da Figura 4). As demais comparações não foram significativas (1-2 e 2-3). Nesses dois últimos casos, as variações são provavelmente devido ao acaso.

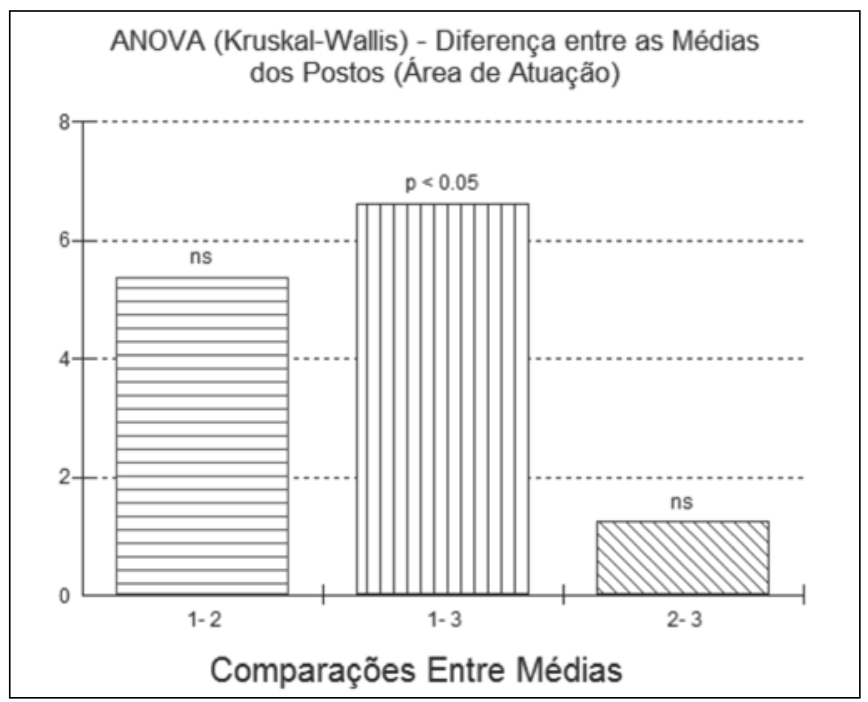

Obs.: $\mathrm{H}=7,6518$ e $\mathrm{p}=0,0218$ (método de Dunn)

Figura 4. Teste ANOVA Kruskal-Wallis $(\alpha<0,05)$ comparativo entre as médias das áreas 1, 2 e 3 de interesse dos candidatos ao mestrado 


\subsection{Perfil dos pós-graduandos do PPGBIO - mestrado}

O PPGBIO, nos quatro editais lançados entre 2006 e 2009, matriculou 49 alunos no curso de mestrado, distribuídos da seguinte forma, por sexo e idade (Tabela 6).

a) Sexo e idade dos pós-graduandos no mestrado

Tabela 6. Média de idade e sexo dos pós-graduandos do PPGBIO (2006 a 2009)

\begin{tabular}{|c|c|c|c|}
\hline Mestrado & $\begin{array}{c}\text { Masculino } \\
\text { (número) }\end{array}$ & $\begin{array}{c}\text { Feminino } \\
\text { (número) }\end{array}$ & $\begin{array}{c}\text { Média de Idade } \\
\text { (anos) }\end{array}$ \\
\hline $1^{\circ}$ Edital 2006 & 10 & 12 & 33 \\
\hline $2^{\circ}$ Edital 2007 & 8 & 8 & 28 \\
\hline $3^{\circ}$ Edital 2008 & 4 & 1 & 28 \\
\hline $4^{\circ}$ Edital 2009 & 3 & 3 & 28 \\
\hline Total & 25 & 24 & 29,3 \\
\hline
\end{tabular}

b) Formação acadêmica

A formação acadêmica dos alunos que ingressaram no mestrado (Tabela 7), apesar de a área de atuação ser específica em Biodiversidade, se classifica nas diversas áreas do conhecimento. Dentre elas, 34 em biológicas, 11 em humanas e quatro em exatas.

Tabela 7. Áreas de formação dos pós-graduandos em números absolutos (2006 a 2009)

\begin{tabular}{|c|c|c|c|}
\hline Mestrado & Exatas & Humanas & Biológicas \\
\hline $1^{\circ}$ Edital 2006 & 3 & 6 & 13 \\
\hline $2^{\circ}$ Edital 2007 & 1 & 4 & 11 \\
\hline $3^{\circ}$ Edital 2008 & 0 & 1 & 4 \\
\hline $4^{\circ}$ Edital 2009 & 0 & 0 & 6 \\
\hline Total & $\mathbf{4}$ & $\mathbf{1 1}$ & $\mathbf{3 4}$ \\
\hline
\end{tabular}


c) Instituição de ensino superior de origem e tempo de conclusão do curso de graduação até o período de inscrição no processo seletivo

Do total de 49 pós-graduandos matriculados no curso de 2006 a 2009, 50\% se formaram no Amapá. A distribuição por região e por ano foi a seguinte (Tabela 8):

Tabela 8. Local de formação acadêmica dos pós-graduandos (2006 a 2009)

\begin{tabular}{|c|c|c|c|}
\hline Mestrado & Amapá & $\begin{array}{c}\text { Região Amazônica } \\
(\mathbf{\%})\end{array}$ & $\begin{array}{c}\text { Outras Regiões } \\
(\%)\end{array}$ \\
\hline $1^{\circ}$ Edital 2006 & 36 & 23 & 41 \\
\hline $2^{\circ}$ Edital 2007 & 38 & 31 & 31 \\
\hline $3^{\circ}$ Edital 2008 & 60 & 20 & 20 \\
\hline $4^{\circ}$ Edital 2009 & 66 & 17 & 17 \\
\hline
\end{tabular}

A média do tempo de conclusão do curso na graduação até o ingresso no mestrado é apresentado na Tabela 9:

Tabela 9. Tempo médio de formação na graduação até o ingresso no mestrado (2006 a 2009)

\begin{tabular}{|c|c|}
\hline Mestrado & Tempo de formação na graduação (anos) \\
\hline $1^{\circ}$ Edital 2006 & 6,6 \\
\hline $2^{\circ}$ Edital 2007 & 3,0 \\
\hline $3^{\circ}$ Edital 2008 & 2,6 \\
\hline $4^{\circ}$ Edital 2009 & 5,0 \\
\hline
\end{tabular}

d) Vínculo empregatício e profissão dos pós-graduandos

Dos 49 pós-graduandos matriculados no período de 2006 a 2009, 28 (57\%) tinham vínculo empregatício e 21 (42\%) não tinham vínculo (Tabela 10) e passaram a receber bolsa da Conservação Internacional, do CNPq e da Capes. Os demais com vínculo empregatício exerciam suas atividades principalmente em instituições públicas, tais como: Instituto Chico Mendes de Conservação da Biodiversidade (ICMBio), Instituto Brasileiro do Meio Ambiente e dos Recursos 
Naturais Renováveis (Ibama), Ministério Público, prefeitura municipal, docentes de Instituições de Ensino Superior (IES) públicas e privadas, professores do ensino médio, Tribunal de Contas do Estado, Prefeitura Municipal, Instituto de Pesquisas Científicas e Tecnológicas do Estado do Amapá, Corpo de Bombeiro Militar, Secretaria de Estado do Meio Ambiente, Secretaria de Estado de Indústria, Comércio e Mineração (Seicom) e Coordenadoria de Vigilância Sanitária.

\section{Tabela 10. Pós-graduandos com vínculo empregatício (2006 a 2009)}

\begin{tabular}{|c|c|c|}
\hline Mestrado & Sim & Não \\
\hline $1^{\circ}$. Edital 2006 & 13 & 9 \\
\hline $2^{\circ}$. Edital 2007 & 11 & 5 \\
\hline $3^{\circ}$. Edital 2008 & 3 & 2 \\
\hline $4^{\circ}$. Edital 2009 & 2 & 4 \\
\hline Total & $\mathbf{2 9}$ & $\mathbf{2 0}$ \\
\hline
\end{tabular}

e) Dissertações defendidas e a área de pesquisa de maior interesse

As defesas correspondem às turmas de 2006 a 2009 (Tabela

11).

\section{Tabela 11. Tema e linha de pesquisa das dissertações defendidas}

\begin{tabular}{|c|l|c|}
\hline No. & \multicolumn{1}{|c|}{ Tema da dissertação } & Linha de pesquisa \\
\hline 1 & $\begin{array}{l}\text { Conselhos gestores de unidades de conservação do } \\
\text { Amapá: percepções sobre as potencialidades e limitações } \\
\text { para efetiva participação dos comunitários }\end{array}$ & Gestão \\
\hline 2 & $\begin{array}{l}\text { Análise de cenário agrícola e de conservação para } \\
\text { paisagens de cerrado no Amapá }\end{array}$ & Gestão \\
\hline 3 & $\begin{array}{l}\text { Caracterização dos padrões espaciais e temporais de } \\
\text { desmatamento na Reserva Extrativista do Rio Cajarí, } \\
\text { estado do Amapá, Brasil }\end{array}$ & Gestão \\
\hline 4 & $\begin{array}{l}\text { Efetividade da lei de crimes ambientais: análise jurídica e } \\
\text { econômica do sistema de implementação legal no Amapá }\end{array}$ & Gestão \\
\hline 5 & $\begin{array}{l}\text { Ocorrência de ariranhas Pteronura brasiliensis (carnívora: } \\
\text { Mustelidae) e interferências antrópicas à espécie no lago } \\
\text { Amanã, Reserva de Desenvolvimento Sustentável Amanã, } \\
\text { Amazonas }\end{array}$ & Caracterização \\
\hline 6 & $\begin{array}{l}\text { Macrofauna edáfica, biomassa microbiana e qualidade do } \\
\text { solo em sistema alternativo ao uso do fogo na agricultura } \\
\text { itinerante da Amazônia }\end{array}$ & Uso sustentável \\
\hline
\end{tabular}




\begin{tabular}{|c|c|c|}
\hline No. & Tema da dissertação & Linha de pesquisa \\
\hline 7 & $\begin{array}{l}\text { Aplicação do sistema de modelagem da qualidade da } \\
\text { água Qual2kw em grandes rios: o caso do alto e médio Rio } \\
\text { Araguari-AP }\end{array}$ & Gestão \\
\hline 8 & $\begin{array}{l}\text { Efeitos de borda sobre a estrutura populacional de árvores } \\
\text { pioneiras em duas regiões da Amazônia brasileira }\end{array}$ & Caracterização \\
\hline 9 & $\begin{array}{l}\text { Avaliação da compensação financeira pela exploração dos } \\
\text { recursos minerais no estado do Amapá }\end{array}$ & Gestão \\
\hline 10 & $\begin{array}{l}\text { Assembleia de morcegos (Chiroptera: Mammalia) da área } \\
\text { de proteção ambiental do Rio Curiaú, Amapá }\end{array}$ & Caracterização \\
\hline 11 & $\begin{array}{l}\text { Caracterização da dinâmica da comunidade de } \\
\text { bacterioplâncton no Estuário do Rio Amazonas (Canal do } \\
\text { Norte) - AP }\end{array}$ & Caracterização \\
\hline 12 & $\begin{array}{l}\text { Ipomea carnea Jacq. ssp. fistulosa (Mart. ex Choisy) D. } \\
\text { Austin: caracterização na Rebio Lago Piratuba - AP, } \\
\text { aspectos morfológicos e estudo tecnológico das sementes } \\
\text { e plântulas visando seu controle }\end{array}$ & Caracterização \\
\hline 13 & $\begin{array}{l}\text { Zoneamento geoambiental do município de Pedra Branca } \\
\text { do Amapari }\end{array}$ & Gestão \\
\hline 14 & $\begin{array}{l}\text { Estrutura populacional, produção e regeneração natural } \\
\text { de castanheiras na Reserva Extrativista do Rio Cajarí-AP }\end{array}$ & Caracterização \\
\hline 15 & Aves de uma savana amazônica no estado do Amapá & Caracterização \\
\hline 16 & $\begin{array}{l}\text { Aspectos morfofisiológicos de Mora paraensis (Ducke) } \\
\text { Ducke Leguminoseae - Caesalpionideae }\end{array}$ & Caracterização \\
\hline 17 & $\begin{array}{l}\text { Composição da fauna de dípteros frugivoros em florestas } \\
\text { de terra firme e de várzea no estado do Amapá }\end{array}$ & Caracterização \\
\hline 18 & $\begin{array}{l}\text { Valoração econômica de ativos naturais urbanos: } 0 \text { caso } \\
\text { da APA da Fazendinha e seu entorno, Macapá - AP }\end{array}$ & Gestão \\
\hline 19 & $\begin{array}{l}\text { Aproveitamento de recursos naturais: estudo da } \\
\text { performance reprodutiva com a aplicação do óleo de } \\
\text { copaíba (Copaifera duckei Dwyer) veiculado em creme } \\
\text { vaginal }\end{array}$ & Uso sustentável \\
\hline 20 & $\begin{array}{l}\text { Análise dos impactos ambientais causados pelos búfalos } \\
\text { asselvajados nos campos inundáveis da Estação Ecológica } \\
\text { de Maracá-Jipioca, costa atlântica do Amapá }\end{array}$ & Gestão \\
\hline 21 & $\begin{array}{l}\text { Estrutura populacional e produção de andiroba em } \\
\text { ambientes de terra firme e várzea no sul do Amapá }\end{array}$ & Caracterização \\
\hline 22 & $\begin{array}{l}\text { Distribuição das espécies endêmicas de peixes de água } \\
\text { doce do Escudo das Guianas }\end{array}$ & Caracterização \\
\hline 23 & $\begin{array}{l}\text { Estrutura e dinâmica de assembleia de aves em resposta } \\
\text { aos ciclos de inundação em um campo de várzea no } \\
\text { município de Macapá, AP }\end{array}$ & Caracterização \\
\hline 24 & $\begin{array}{l}\text { Modelagem de escoamento ambiental como subsídio à } \\
\text { gestão de ecossistemas aquáticos no baixo Igarapé da } \\
\text { Fortaleza-AP }\end{array}$ & Gestão \\
\hline 25 & $\begin{array}{l}\text { Uso da geotecnologia como subsídio à gestão ambiental } \\
\text { de unidade de conservação: estudo de caso da Estação } \\
\text { Ecológica do Jari, Laranjal do Jari, Amapá }\end{array}$ & Gestão \\
\hline
\end{tabular}




\begin{tabular}{|c|l|c|}
\hline No. & \multicolumn{1}{|c|}{ Tema da dissertação } & Linha de pesquisa \\
\hline 26 & $\begin{array}{l}\text { Influências de variáveis meteorológicas na riqueza, } \\
\text { abundância e diversidade de espécies anofélicas (Diptera: } \\
\text { culicidade) em área rural do município de Macapá, Amapá, } \\
\text { Brasil }\end{array}$ & Caracterização \\
\hline 27 & $\begin{array}{l}\text { Fauna silvestre ex-situ no estado do Amapá: utilização, } \\
\text { apreensão e destinação }\end{array}$ & Gestão \\
\hline 28 & $\begin{array}{l}\text { "Maus-tratos contra os animais” viro o bicho!: } \\
\text { antropocentrismo, ecocentrismo e educação ambiental } \\
\text { em Serra do Navio (Amapá) }\end{array}$ & Gestão \\
\hline 29 & $\begin{array}{l}\text { Efeitos de borda e aspectos ecológicos sobre moscas } \\
\text { varejeiras (Diptera: Calliphosidae) na Amazônia Oriental }\end{array}$ & Caracterização \\
\hline 30 & $\begin{array}{l}\text { Anatomis ecológica de lenho de Mora paraensis (Ducke) } \\
\text { Ducke em várzea estuarina no estado do Amapá }\end{array}$ & Caracterização \\
\hline 31 & $\begin{array}{l}\text { "Tudo é remédio": estudo de práticas curativas em } \\
\text { Maruanum-AP }\end{array}$ & Caracterização \\
\hline 32 & $\begin{array}{l}\text { Aproveitamento de recursos naturais da biodiversidade } \\
\text { amapaense: óleo fixo do piquiá (Caryocar villosum (Aubl.) } \\
\text { Pers.) como anti-inflamatório tópico }\end{array}$ & Uso sustentável \\
\hline 33 & $\begin{array}{l}\text { Ecologia de Lisapsus bolivianus (Anura: Hylidae) na Área } \\
\text { de Proteção Ambiental do Rio Curiaú, Macapá, Amapá, } \\
\text { Brasil }\end{array}$ & Caracterização \\
\hline
\end{tabular}

Considerando as três linhas de pesquisa do programa, o percentual das dissertações defendidas se encontra subdividido em: $52 \%$ em caracterização (17), 39\% em gestão e conservação (13) e 9\% em uso sustentável da biodiversidade (3). Dos 33 que defenderam, 67\% tinham formação acadêmica na área de biológicas, 21\% da área de humanas e $12 \%$ da área de exatas. Além disso, 56\% mantinham vínculo empregatício e $44 \%$ eram bolsistas. Dos 21 bolsistas contemplados nos anos de 2006 a 2009, 15 defenderam a dissertação. Entretanto, seis se desligaram do curso.

\section{Discussão dos resultados}

No estado do Amapá, a Unifap foi pioneira com os primeiros cursos de pós-graduação stricto senso a partir de 2006. No entanto, desde seu início, havia uma demanda reprimida de profissionais na expectativa de oportunidades de cursos de mestrado e doutorado do PPGBIO. 
Esse fato talvez explique a elevada média de idade dos candidatos em nivel de mestrado (30 anos), principalmente nos dois primeiros editais do programa. Nesse aspecto, a consideramos como relativamente elevada, principalmente com a atual tendência de novos candidatos (egressos da graduação da própria Unifap) com faixa etária menor a cada ano.

Comparando o parâmetro idade, observamos que ela não foi significativamente diferente entre os candidatos ao mestrado (média de 30 anos) e os aprovados no curso (média de 29 anos). Essa média de idade pode ser considerada alta para o ingresso no mestrado, que deveria receber, preferencialmente, profissionais recém-formados dos cursos de graduação.

Essa tendência parece estar em concordância com o PNPG (2010), em que os índices oficiais apontam para uma "formação pós-graduada longa e tardia no Brasil, que deve ser revertida para patamares etários mais baixos, a fim de que haja renovação e longevidade suficientes para suprir as necessidades do país no processo de reposição e expansão de seus quadros atuantes na ciência e tecnologia".

Em relação à área de formação acadêmica do candidato ao mestrado, o destaque foi para a área de biológicas, seguida pelas áreas de humanas e exatas. Esse padrão foi mantido para os que foram aprovados e matriculados no curso, obedecendo a mesma proporção no tempo. A maior concentração de profissionais vindos da área de biológicas reflete a identificação com a área de concentração, matriz curricular e área de pesquisa dos docentes.

Na avaliação dos anos de 2006 a 2009, tanto para os candidatos quanto para os que ingressaram no mestrado, predominaram os que obtiveram formação acadêmica no estado do Amapá (51\%) e na região amazônica (26\%). Essa demanda regional tende a se manter elevada até a aprovação de outros programas pela Capes com perfil semelhante, fato que já está ocorrendo na atualidade, com a implementação de novos programas de mestrado no Amapá. 
Com base na análise supracitada, observa-se que, em função da distribuição regional dos cursos de pós-graduação por nível, indica a concentração de mais de $50 \%$ do seu total na região Sudeste. Assim, de acordo com o PNPG (2010), nas demais regiões brasileiras, há um decréscimo do percentual de concentração de cursos, na seguinte ordem: regiões Sul, Nordeste, Centro-Oeste e Norte, sendo que nesta os percentuais são de cerca de $5 \%$ para os cursos de mestrado, revelando uma marcada assimetria em relação à região brasileira de maior concentração, a Sudeste.

Quanto ao tempo de conclusão do curso de graduação, tanto os candidatos quanto os aprovados para o mestrado mantiveram um período até o ingresso no curso muito próximo, entre 4,9 anos e 4,3 anos, respectivamente. Contudo, observou-se uma tendência de diminuição desse período. Nesse aspecto, o PPGBIO tem cumprido um papel fundamental que é o de reduzir a pressão da demanda reprimida desses profissionais no mercado de trabalho e, ao mesmo passo, permitir que os jovens egressos dos cursos de ciências biológicas e áreas correlatas sejam também absorvidos pelo programa, com taxas cada vez maiores, uma vez que a cada ano o tempo de formação até o ingresso tem diminuído.

A maioria dos que se inscreveram e foram aprovados possui vínculo empregatício (66\% e 57\%, respectivamente). Além disso, esses números também mostram que, para o período avaliado, pelo menos $1 / 3$ desses pós-graduandos dependeriam de bolsas de fomento à pesquisa. Até o ano 2009, essas demandas por bolsas têm sido plenamente contempladas pelo PPGBIO (CNPq/Capes/Cl e outros projetos), e supridas as demandas críticas para os alunos que não possuem emprego, permitindo certo equilíbrio entre a oferta e a demanda de bolsas até o presente momento.

Em relação ao perfil profissional, apenas 18\% dos aprovados eram compostos por professores da rede pública de ensino. Esse número foi relativamente baixo em relação aos candidatos inscritos, que eram cerca de 60,75\% que atuavam na área educacional. Esses números sugerem que muitos profissionais da área da educação 
(licenciatura em biologia e afins) buscam o PPGBIO por ser uma das poucas alternativas de curso em nível de mestrado e doutorado disponivel no estado, elevando o nível de concorrência pelas poucas vagas disponíveis.

Quanto à variável área de pesquisa do curso de mestrado de maior interesse, durante a seleção, os candidatos optaram por gestão e conservação da biodiversidade, em detrimento das demais. Mas, para os aprovados no mestrado, considerando as 33 defesas atualmente realizadas, a área de caracterização da biodiversidade foi a predominante, indicando que o perfil das preferências pelas áreas é dinâmico, modificando-se com o tempo. Além disso, percebe-se que essa variação depende também da disponibilidade de vagas do corpo docente no programa.

Ao se avaliar o perfil do egresso, vale ressaltar que os profissionais mantiveram-se em suas funções profissionais no estado do Amapá. Alguns profissionais, principalmente os bolsistas, foram aprovados em concursos públicos federal e estadual em áreas estratégicas, dando destaque às atividades técnico-científicas em unidades de conservação que formam o Corredor da Biodiversidade, como é o caso do ICMBio, da Sema e Embrapa. Os demais permaneceram no estado, prestando serviços de consultorias técnicas, principalmente na área de licenciamento ambiental e plano de manejo de áreas de conservação, como, por exemplo, na Floresta Nacional do Amapá (Flona-AP), no Parque Nacional Montanhas do Tumucumaque, na Reserva Biológica do Lago Piratuba, entre outros. Dentre os 33 egressos do mestrado, nove atualmente estão cursando o doutorado do PPGBIO, com perspectiva de conclusão até 2015.

O PNPG sugere que os principais desafios desse profissional na região é reduzir incertezas, ter capacidade de fazer previsões, oferecer soluções para o tamanho e a distribuição geográfica, valores e serviços da biodiversidade e taxa de perda da biodiversidade, efetividade dos esforços de conservação, sustentabilidade e limiares do uso da biodiversidade, e equitabilidade da repartição dos benefícios. De certa forma, o PPGBIO promove a redução da demanda reprimida de 
profissionais que procuram se especializar na área e, ao mesmo tempo, forma recursos humanos que atendem ao perfil e às perspectivas preconizadas pelo Corredor da Biodiversidade e pelo PNPG.

Do total de 49 pós-graduandos matriculados no mestrado do PPGBIO entre 2006 e 2009, ocorreu a integralização de 33, indicando uma eficiência de $67 \%$, e $33 \%$ de evasão ou desistência. No decorrer desses quatro anos de funcionamento do curso, 16 alunos, por diversos motivos, perderam seu vínculo com a pós-graduação. Essa desvinculação ocorreu normalmente a pedido ou em decorrência de situações previstas no regimento interno do curso ou até mesmo devido à incompatibilidade do emprego em relação à dedicação total ao curso. Vale ressaltar que pelo menos seis desistentes eram bolsistas e os demais mantinham vínculo empregatício. Considerando os 10 restantes com vínculo empregatício que desistiram ou foram desligados do curso, um dos fatores indutores foi a constatação da não liberação integral de suas atividades profissionais para cursar com exclusividade uma pós-graduação, sendo esse talvez o principal motivo que resultou na impossibilidade de dedicação exclusiva ao curso, inibindo bons rendimentos ou a desistência antecipada.

Com base nos números discutidos anteriormente, o PPGBIO vem obtendo avanços em divulgação científica, que podem ser observados a partir das pesquisas concluídas (Tabela 11), sendo $30 \%$ publicadas em periódicos ou capítulos de livros nacionais e internacionais. Além disso, os 30\% restantes continuam submetendo trabalhos científicos para editores de periódicos. Portanto, a obtenção do título de mestre possibilitou maior inserção científica de trabalhos realizados no bioma amazônico, elevando as perspectivas positivas para seu aprofundamento, pois 30\% dos mestres titulados no período de 2006 a 2009 já ingressaram em curso de doutorado até 2011.

Além disso, essa tendência de aumento do número de mestres formados se alinha com a importância da geração de informações estratégicas para o estado, que apresentam perspectivas positivas em relação aos diversos ecossistemas do estado do Amapá que compõem o Corredor da Biodiversidade e que, por sua vez, necessita de profissionais capacitados para atuar nesse setor. 


\section{Considerações finais}

Atualmente, o Programa de Pós-Graduação em Biodiversidade Tropical (PPGBIO) conta com o apoio financeiro da Capes e do CNPq, oferecendo anualmente 25 vagas no mestrado e 15 no doutorado, sendo o pioneiro nesta modalidade da área de pesquisa em biodiversidade tropical no Brasil. A ideia de um sistema inovador e descentralizado para a formação de recursos humanos resultou efetivamente na geração de conhecimento representado pelas dissertações defendidas.

O PPGBIO tem sido consistente com vários planos e políticas do Governo Federal, com destaque para a Política Nacional da Biodiversidade, o Plano Estratégico Nacional de Áreas Protegidas e o plano estratégico do Ministério da Ciência, Tecnologia e Inovação para a Amazônia. Essas políticas visam estimular a formação e a fixação de recursos humanos qualificados nos estados mais periféricos do centro de decisão política do Brasil, tal como o estado do Amapá.

O PPGBIO também está alinhado com o novo Plano Nacional de Pós-Graduação (2011-2020), que visa corrigir as assimetrias existentes na distribuição geográfica e qualificação dos programas de pósgraduação brasileiros, além de testar novos modelos de associação entre instituições na criação e implantação de programas de pósgraduação com o objetivo de formar profissionais qualificados em áreas estratégicas e em setores vocacionais regionais relevantes, como a pesquisa sobre a caracterização, gestão e o uso da biodiversidade tropical.

Na visão dos autores, a avaliação do curso nesse primeiro triênio é positiva. As razões são decorrentes dos indicadores analisados anteriormente, sendo possivel estimar ainda uma melhoria efetiva dos quadros de recursos humanos de alto nível técnico que permaneceram no estado do Amapá. Além disso, as perspectivas profissionais tendem a crescer em relação às novas oportunidades de mercado de trabalho desse setor estratégico, haja vista que as políticas públicas ambientais do estado Amapá não se modificaram ao longo desta última década e, pelo contrário, tendem a se intensificar e a se expandir em função de sua vocação regional. 
De acordo com o PNPG, apesar do sistema de CT\&l na região Norte ainda se encontrar subdimensionado para estimular o desenvolvimento econômico e social da região, constatamos que ainda é necessário reconhecer que as estratégias que podem mudar as deficiências regionais requerem investimentos em C\&T, com destaque para a formação e fixação de recursos humanos. Por essa razão, a qualificação de pessoal na Amazônia é o elemento chave para atender às expectativas de desenvolvimento do sistema de C\&T, interrompendo o ciclo das assimetrias intra e inter-regionais.

Portanto, há a necessidade de reforçar ações para a capacitação de pessoal compatível com a escala amazônica, com geração de renda e inclusão social, expansão da capacitação para as áreas não contempladas e cooperação intrarregional. A concepção de programas de apoio à cooperação inter-regional, nacional e internacional para a qualificação de pessoal para a Amazônia é de fundamental importância. A região Norte concentra $13,7 \%$ da população brasileira e colabora com aproximadamente $8 \%$ do $\mathrm{PIB}$, mas tem recebido apenas $4 \%$ dos recursos de C\&T do País.

O desenvolvimento regional amazônico encontra dificuldades quando comparado ao das outras regiões brasileiras devido ao seu baixo Índice de Desenvolvimento Humano (IDH) e à sua baixa produtividade em C\&T, que têm origem no número escasso de cursos de pós-graduação de nível de doutorado aí implantados. Essa situação é ainda agravada pela ausência de políticas eficientes para a fixação de doutores e pelas deficiências em todos os níveis de ensino. Pois, apesar de representar cerca de 60\% do território brasileiro, abrigar aproximadamente $13 \%$ de sua população e contribuir com $8 \%$ do PIB nacional, a Amazônia possui pouco mais de quatro mil doutores, metade dos quais não está envolvido com a produção de informações e qualificação de pessoal em nível de pós-graduação.

Para solucionar as deficiências, há a necessidade de ações para a capacitação de pessoal compatível com a escala amazônica, com a necessidade de geração de renda e inclusão social,com a expansão da capacitação para as áreas não contempladas e com a cooperação intra 
e inter-regionais, a exemplo da própria concepção do PPGBIO, com suas parcerias institucionais.

Com base no processo de implantação do PPGBIO, é notória a percepção de que o programa tem contribuído com a promoção e a emancipação doCorredor de Biodiversidade, especialmentefomentando a formação qualificada de recursos humanos para o enfrentamento dos imensos desafios dessa área estratégica para o Brasil. Portanto, esse caminho parece ser a melhor estratégia e o melhor ponto de partida para potencializar a proteção e o uso sustentável do capital natural renovável do Amapá, elevando a perspectiva de desenvolvimento humano e ecológico com base em uma economia mais inovadora a ser implementada na atualidade e em um futuro próximo.

Recebido 06/04/2011

Aprovado 10/05/2012

\section{Referências bibliográficas}

AYRES, M. et al. Biostat 5.0. Aplicações estatísticas nas áreas das ciências biológicas e médicas. 5a. Belém: Editora IDSM/MCT, 2007.. 364p.

BECKER, B. K. Revisão das políticas de ocupação da Amazônia: é possível identificar modelos para projetar cenários? Parcerias Estratégicas, n. 12, p. 135-159, 2001.

CELENTANO, D.; VERÍSSIMO, A. O Avanço da Fronteira na Amazônia: do boom ao colapso. O Estado da Amazônia: Indicadores. n. 2. Belém: Imazon, 2007. 44p.

CUNHA, H. F. A. Caderno de Resumos: Dissertações. Programa de PósGraduação em Biodiversiadade Tropical. PPGBIO/UNIFAP. Macapá Amapá. 2011. 35 p.

DINIZ, C. W. P. Universidades da Amazônia brasileira: o pecado e a penitência. Belém: Universidade Federal do Pará, 1996. 
PLANO NACIONAL DE PÓS-GRADUAÇÃO - PNPG. 2011-2020. Brasília, DF: Capes, 2010.

SCHAEFFER-NOVELLI, Y. Grupo de ecossistemas: manguezal, marisma e apicum. São Paulo:, 2001. Disponível em: http://www.anp.gov.br/ brasil-rounds/round8/round8/guias_r8/perfuracao_r8/\%C3\%81reas_ Priorit\%C3\%A1rias/manguezal_marisma_apicum.pdf. Acesso em: 05 mar. 2012.

SILVA, J. M. C. da. Corredor da Biodiversidade do Amapá. Belém: ClBrasil, 2007.

SILVA, W. C. Políticas públicas: viabilidade econômica do pagamento por serviços ambientais no estado do Amapá utilizando análise de risco. 2011. Dissertação (Mestrado em Direito Ambiental e Políticas Públicas) Programa de Pós-Graduação de Mestrado em Direito Ambiental e Políticas Públicas, Universidade Federal do Amapá, Macapá.

UNIVERSIDADE FEDERAL DO AMAPÁ. Projeto Político Pedagógico do Programa de Pós-Graduação em Biodiversidade Tropical (PPGBIO). Macapá: Unifap, 2005.

Regimento Interno do Programa de Pós-Graduação em Biodiversidade Tropical. Macapá: Unifap, 2008.

VIEIRA, I. C. G.; SILVA, J. M. C. da; TOLEDO, P. M. de. Estratégias para evitar a perda de biodiversidade na Amazônia. Estudos Avançados, 19, (54), p. 153-164, 2005. 